Review

\title{
Supramolecular Polymer Nanocomposites for Biomedical Applications
}

\author{
Xiumei Li ${ }^{1,2}$, Wanjia Xu ${ }^{1}$, Yue Xin ${ }^{1}$, Jiawei Yuan ${ }^{1}$, Yuancheng Ji ${ }^{1}$, Shengnan Chu ${ }^{1}$, Junqiu Liu ${ }^{1,2}$ \\ and Quan Luo ${ }^{1,3, *}$ \\ 1 State Key Laboratory of Supramolecular Structure and Materials, College of Chemistry, Jilin University, \\ 2699 Qianjin Street, Changchun 130012, China; lixiumei_chem@163.com (X.L.); xuwj1997@163.com (W.X.); \\ xinymavis@gmail.com (Y.X.); yuanjw1318@mails.jlu.edu.cn (J.Y.); jiyc1216@gmail.com (Y.J.); \\ 15732622036@163.com (S.C.); junqiuliu@jlu.edu.cn (J.L.) \\ 2 College of Material, Chemistry and Chemical Engineering, Hangzhou Normal University, \\ Hangzhou 311121, China \\ 3 Key Laboratory of Emergency and Trauma, Ministry of Education, College of Emergency and Trauma, \\ Hainan Medical University, Haikou 571199, China \\ * Correspondence: luoquan@jlu.edu.cn
}

check for updates

Citation: Li, X.; Xu, W.; Xin, Y.; Yuan, J.; Ji, Y.; Chu, S.; Liu, J.; Luo, Q. Supramolecular Polymer

Nanocomposites for Biomedical Applications. Polymers 2021, 13, 513 https://doi.org/10.3390/ polym13040513

Academic Editors:

Donatella Duraccio,

Maria Giulia Faga and

Giovanna Gomez D’Ayala

Received: 26 January 2021

Accepted: 3 February 2021

Published: 9 February 202

Publisher's Note: MDPI stays neutral with regard to jurisdictional claims in published maps and institutional affiliations.

Copyright: (c) 2021 by the authors. Licensee MDPI, Basel, Switzerland. This article is an open access article distributed under the terms and conditions of the Creative Commons Attribution (CC BY) license (https:// creativecommons.org/licenses/by/ $4.0 /)$
Abstract: Polymer nanocomposites, a class of innovative materials formed by polymer matrixes and nanoscaled fillers (e.g., carbon-based nanomaterials, inorganic/semiconductor nanoparticles, metal/metal-oxide nanoparticles, polymeric nanostructures, etc.), display enhanced mechanical, optoelectrical, magnetic, catalytic, and bio-related characteristics, thereby finding a wide range of applications in the biomedical field. In particular, the concept of supramolecular chemistry has been introduced into polymer nanocomposites, which creates myriad "smart" biomedical materials with unique physicochemical properties and dynamic tunable structures in response to diverse external stimuli. This review aims to provide an overview of the chemical composition, morphological structures, biological functionalities, and reinforced performances of supramolecular polymer nanocomposites. Additionally, recent advances in biomedical applications such as therapeutic delivery, bioimaging, and tissue engineering are also discussed, especially their excellent properties leveraged in the development of multifunctional intelligent biomedical materials.

Keywords: supramolecular polymer nanocomposite; biomedical application; therapeutic delivery; bioimaging; tissue engineering

\section{Introduction}

With the rapid development of materials science, higher requirements are being put forward for the structure, property, and functional diversity of polymer materials. Additionally, there is a growing emphasis on the personalized design of materials to meet special requirements, especially in the field of biomedicine. Polymer nanocomposites, as a class of innovative materials, attract considerable attention because of their programmable functions and outstanding properties $[1,2]$. From the perspective of chemical composition, polymer nanocomposites are matrix-filler combinations composed of polymer matrixes and nanoscaled reinforcing phases (either organic or inorganic constituents). Their performance is prominently dependent on the inherent properties of polymer matrixes, the reinforcing effects from nanofillers, and the production processes. The incorporation of organic or inorganic phases into polymer matrixes further upgrades their new properties such as enhanced mechanical, good optoelectrical, magnetic, catalytic, and biorelated characteristics [3-5]. By choosing appropriate nanofillers, loading amounts, and processing methods, it is even possible to obtain customized functional nanocomposites.

On the basis of specificity and reversibility, supramolecular chemistry provides the possibility of dynamic and intelligent control of polymer nanocomposites. Supramolecular 
polymer nanocomposites, which perfectly combine the advanced properties of polymer nanocomposites with the advantages of supramolecular chemistry, hold great promise as a novel class of multifunctional "smart" materials. Unlike covalent polymer nanocomposites, supramolecular polymers nanocomposites are totally or partially governed by various supramolecular interactions, including hydrogen bonding, metal coordination, $\pi-\pi$ interactions, host-guest interactions, and electrostatic interactions. Basically, supramolecular interactions are incorporated into each stage of polymer nanocomposites preparation such as polymer interconnections, the coupling between polymer matrix and nanofiller, or even both. The intrinsic directivity and reversibility of supramolecular interactions not only allow efficient access to molecular order and morphology control, but also endow supramolecular polymer nanocomposites with fascinating dynamic structures in response to diverse external stimuli (e.g., such as $\mathrm{pH}$, temperature, ionic strength, light, voltage, etc.) [6-10]. These features are absolutely attractive and desired by materials science, thus paving the way for a wide range of applications. In general, supramolecular polymer nanocomposites integrate the advantages of dynamics, stability, and versatility, which may inspire future revolutions in many fields, especially biomedicine.

In this review, we summarize the chemical composition, biomedically relevant properties, and versatile applications of several representative supramolecular polymer nanocomposites in terms of their structure-property relationship. In particular, we highlight how scientists reinforce material performance through rational design, thereby leveraging their various applications in biomedical field including therapeutic delivery, bioimaging, and tissue engineering.

\section{Classification of Supramolecular Polymer Nanocomposites}

Typically, supramolecular polymer nanocomposites can be categorized into three main types according to the filler constituents (carbons, inorganic/semiconductor, metal/metal oxide). We will discuss some examples below, where different functional nanomaterials are integrated into a polymer matrix to improve stability and mechanical strength, or even give brand-new properties.

\subsection{Carbon-Based Supramolecular Polymer Nanocomposites}

Carbon-based nanomaterials, including 0D fullerenes, 1D carbon nanotubes (CNTs), 2D graphene, etc., represent an important group of nanofillers. The prominent mechanical properties, and electrical and thermal conductivities make them ideal functional additives to incorporate multifunctionality into polymers. Typically, the inclusion of CNTs or graphene can significantly improve the mechanical, electrical, and thermal properties of the final materials [11-13], thereby showing a broad application prospect. For example, Tang et al. [14] developed a single-wall carbon nanotubes (SWCNTs)-reinforced supramolecular polymer hydrogel via in situ free radical polymerization. Owing to the reinforcement effect of the SWCNTs, the resulting nanocomposites showed both an improved tensile strength (over $300 \%$ ) and a faster electromechanical response capability. Similar enhancements were also observed in graphene reinforced polymer composites. Chu and co-workers [15] fabricated a novel electro-responsive nanocomposite polymer hydrogels by incorporating the reduced graphene oxide (rGO) nanosheets into poly(2-acrylamido-2-methylpropane sulfonic acid-coacrylamide) (poly(AMPS-co-AAm)) networks via two-step reduction (Figure 1a). As a result, both the tensile strength and compressive strength of the nanocomposite hydrogels are remarkably improved by the hydrogen bond networks between rGO nanosheets and poly(AMPS-co-AAm) chains. Moreover, the inherent electronic conductivity of rGO nanosheets further endows these nanocomposite hydrogels with excellent electro-responsive properties for possible applications as "soft cantilevers" and "soft grippers". 
(a)
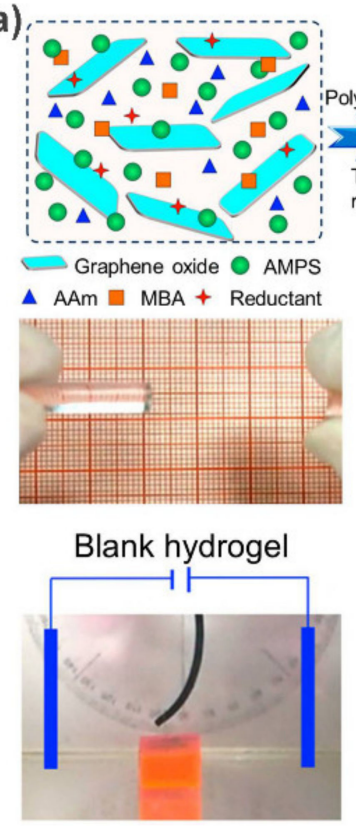
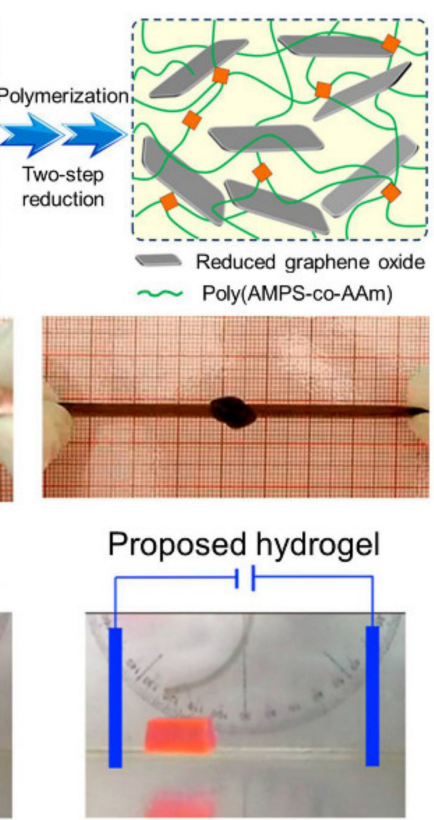

(b)
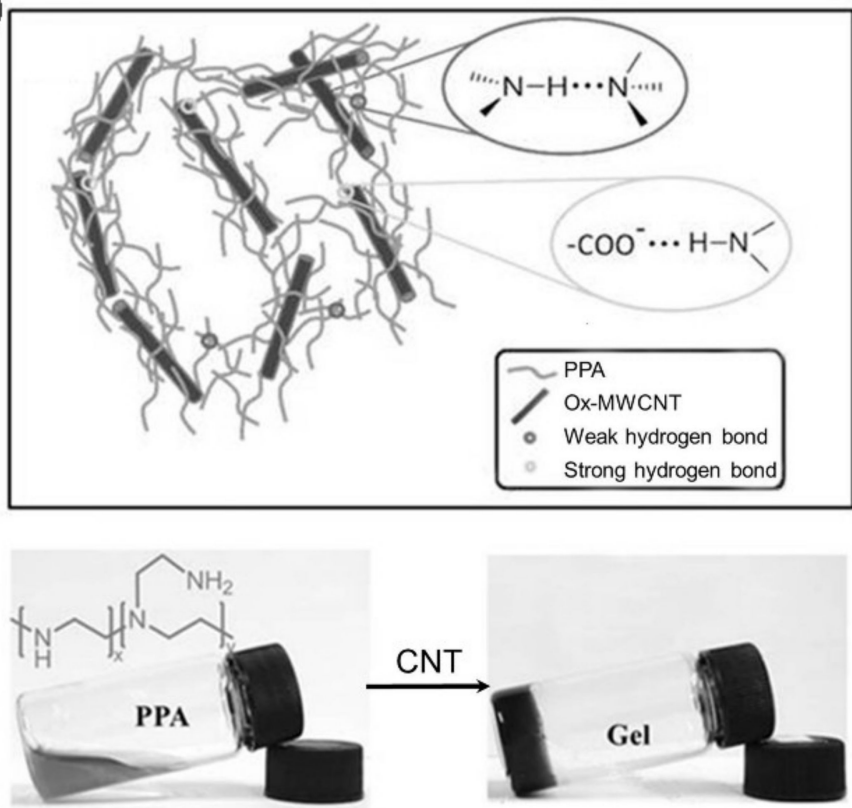

Figure 1. (a) Schematic representation of the fabrication of rGO/poly(AMPS-co-AAm) nanocomposite hydrogels. Photographs show their improved mechanical properties and obvious electro-responsive bending behaviors. (b) The formation of ox-MWCNTs/PPA hydrogels via hierarchical hydrogen bonds. Adapted with permission from Refs. [15,16].

Besides the above improvements in mechanical and electrical performances, CNTs and graphene can also work as crosslinkers to guide the formation of supramolecular carbon-based polymer nanocomposites through non-covalent interactions. Especially for oxidized CNTs (ox-CNTs) and graphene oxide (GO), the introduction of various amphiphilic oxygen-containing groups (carbonyl, carboxyl, hydroxyl, and epoxide) on the surface of CNTs and graphene not only facilitates their dispersion in aqueous media, but also allows for the noncovalent interactions with polymer chains through hydrogen bonding or van der Waals force, thus paving the way for the preparation of supramolecular polymeric nanocomposites. Accordingly, carbon-based supramolecular polymer nanocomposites have been widely used to engineer self-healing and stimuli-responsive materials. For example, Zhang et al. [16] fabricated a multifunctional nanocomposite hydrogel based on oxidized multi-walled carbon nanotubes (ox-MWCNTs) and polyethylene polyamine (PPA), where hierarchical hydrogen bonds (the combination of hydrogen bonds with different strength) act as ingenious driving forces for the hydrogel preparation and functional design (Figure 1b). As expected, the resultant ox-MWCNTs/PPA hydrogels integrate thermal responsiveness, $\mathrm{pH}$ responsiveness, and self-repair properties due to the dynamic and stimulus-responsive nature of the hydrogen bond network. On the other hand, attributing the unique photothermal response property of ox-MWCNTs, a fast gel-sol transition could be triggered by near-infrared (NIR) light. In this case, the gel could transform to the solution within 2 min upon exposure to NIR light, and then back to the gel state within 3 min under visible light. Similar self-repair behavior was also observed by Yan et al. [17] on chitosan/GO hydrogels. These features are particularly desirable for biomedical applications, such as tissue engineering and drug delivery, depicting a bright application prospect.

In addition, a supercritical $\mathrm{CO}_{2}\left(\mathrm{SC}-\mathrm{CO}_{2}\right)$-assisted process is able to reduce and exfoliate $\mathrm{GO}$ powders to improve their electrochemical properties. Sarno M. et al. systematically studied the effect of SC- $\mathrm{CO}_{2}$ processing on $\mathrm{GO}[18]$ and subsequently applied this process to the preparation of polymer/GO-based supercapacitor electrodes [19]. At the optimized GO loading $(60 \% w / w)$, the supercapacitor reaches a very high energy density of $79.2 \mathrm{Wh} \mathrm{kg}^{-1}$ at a power density of $234 \mathrm{~W} \mathrm{~kg}^{-1}$ and exhibits excellent electrochemical properties. 


\subsection{Inorganic/Semiconductor Nanoparticle-Based Supramolecular Polymer Nanocomposites}

Some inorganic nanoparticles, such as silica nanoparticles, mesoporous silica nanoparticles (MSNs), nanoclays, calcium phosphates, and bioactive glasses, play an important role in the mechanical and functional reinforcement of polymer materials. They have motivated extensive research interest due to their excellent biocompatibility, unique bioactive properties, and high mechanical and thermal stability [5]. Recently, Scherman et al. [20] developed a supramolecular fiber with excellent tensile and damping properties from a $\mathrm{SiO}_{2}$ nanoparticle-reinforced polymer hydrogel. As shown in Figure $2 \mathrm{a}$, the hydrogels contain two main components: methyl viologen (MV)-functionalized polymer-grafted silica nanoparticles (P1) and a linear semicrystalline polymer H1 (hydroxyethyl cellulose functionalized with naphthalene $(\mathrm{Np})$ isocyanate). Cucurbit[8]uril (CB[8]) acts as a crosslinker to trigger the self-assembly for the formation of stable and dynamic 3D network via host-guest interactions. Attractively, uniform supramolecular fibers that exhibit an extremely high damping capacity of $64.2 \pm 2.2 \%$ and remarkable tensile properties can be readily drawn from this hydrogel to compete with viscose, artificial silks, and hair.

Similarly, clays are introduced as physical crosslinking points to improve the physical and mechanical properties of polymeric matrix. As a typical example, Aida and co-workers [21] developed a high-water-content (96\%-98\% water) hydrogel through the self-assembly of sodium polyacrylate (ASAP) pretreated clay nanosheets (CNSs) and dendritic molecular binders (Gn-binders, $n=1-3$ ) decorated with multiple guanidinium ions at the ends of dendrites. CNSs are first electrostatically wrapped by ASAP to facilitate their dispersion in water. Subsequently, the cationic guanidine group quickly adheres to the anionic surface of CNSs to form mechanically tough ( $\mathrm{G}^{\prime}$ up to $0.5 \mathrm{MPa}$ ) and transparent hydrogel. Additionally, the hydrogel displays self-healing behavior, as the assembly is driven by non-covalent interactions, which provides many possible applications, such as transporting biological activities. Beyond these improvements, these inorganic nanoparticles are also noted for fascinating bioactive properties. Calcium phosphates and bioactive glasses are frequently used to develop nanocomposite bioscaffolds with excellent mechanical and biological properties for tissue engineering applications [22,23].

Semiconductor quantum dots (QDs) possess several attractive advantages such as broad excitation and narrow emission spectra, high quantum yield, and unique sizedependent emission [24], making them ideal fluorescent additive for polymer matrix. In these cases, polymers exhibit rare optical properties, thereby opening up a new avenue for their applications in optical imaging. For example, a QD-reinforced polypeptide hybrid nanogel was fabricated by Liu and co-workers for targeted imaging [25]. By incorporating multiple functional domains into a polymer chain, a coiled-coil polypeptide ( $\left.\mathrm{PC}_{10} \mathrm{ARGD}\right)$ was fabricated. As shown in Figure $2 b, \mathrm{PC}_{10}$ ARGD could be attached to the surface of GSH-capped CdSe-ZnS QDs by metal coordination, leading to a sandwich hydrogel layer surrounding the QDs formed through the association of the coiled-coil P domain. The formation of nanogel not only decreases the cytotoxicity to both HeLa cells and NIH 3T3 cells, but also promotes the imaging specificity due to the targeting effects of the RGD motif.

\subsection{Metal/Metal-Oxide Nanoparticle-Based Supramolecular Polymer Nanocomposites}

Metal [26-28] (gold, silver, copper, and other noble metals) and metal-oxide [29] (such as $\mathrm{Fe}_{2} \mathrm{O}_{3}, \mathrm{Fe}_{3} \mathrm{O}_{4}, \mathrm{Al}_{2} \mathrm{O}_{3}, \mathrm{ZnO}$, and $\mathrm{TiO}_{2}$ ) nanoparticles exhibit many novel properties different from conventional solids, which enable the fabrication of advanced functional materials for optoelectrical, magnetic, catalytic, and biomedical applications. In particular, a wide variety of high-performance supramolecular polymer nanocomposites can be developed by combining them with polymers. Such nanocomposites are commonly prepared in two approaches: in situ synthesis of these nanoparticles in the polymer networks, or embedding surface-functionalized nanoparticles into the polymer networks. This combination not only inhibits the oxidation and agglomeration of metal nanoparticles to fully exert their specific properties, but also reduces the consumption of metal (especially noble metal), thereby leading this become a hot spot of materials science. 
(a)
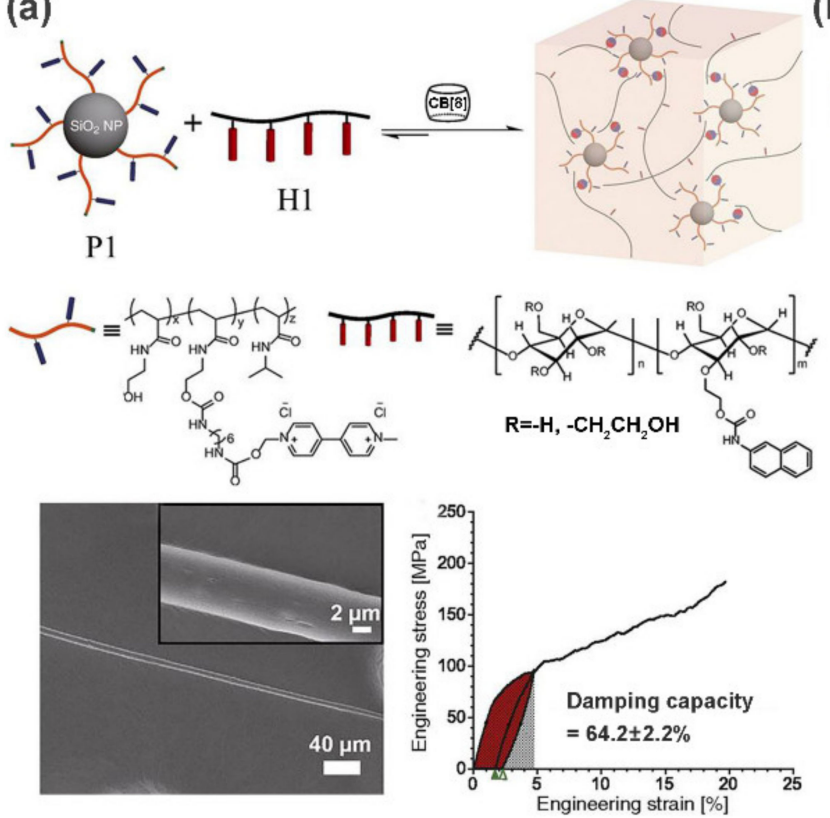

(b)
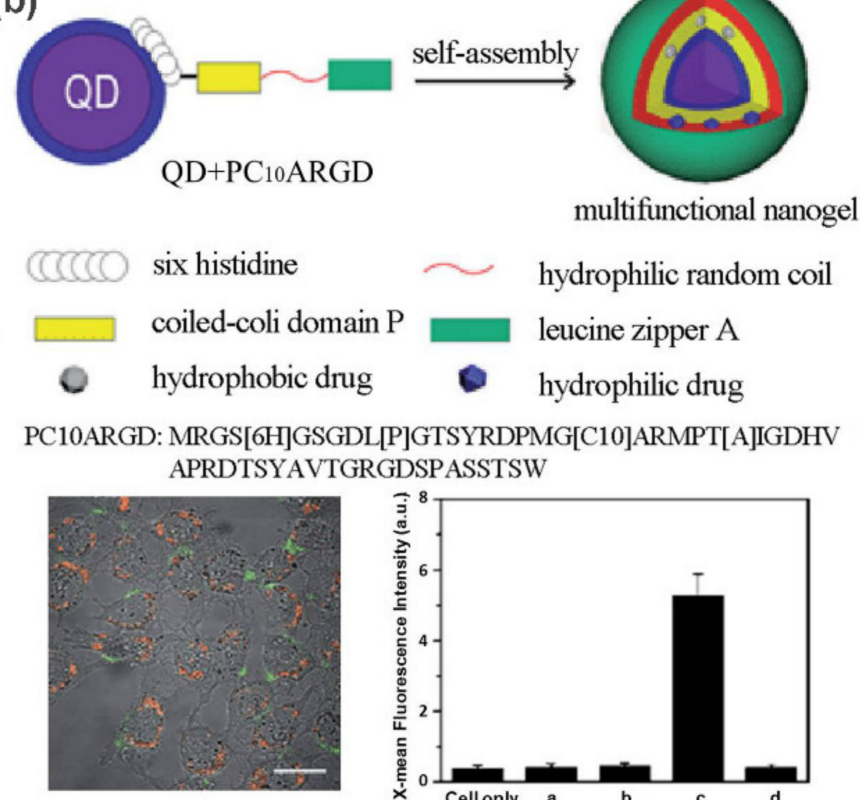

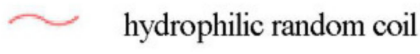

leucine zipper A

hydrophilic drug multifunctional nanogel

Figure 2. (a) CB [8]-mediated self-assembly of MV-functionalized silica nanoparticles and linear semicrystalline polymer into supramolecular nanocomposite hydrogel. Supramolecular fibers can be drawn from this hydrogel and exhibit a high damping capacity. (b) Schematic illustration of the formation process of QD/PC 10 ARGD nanogel. Confocal fluorescence image and flow cytometry analysis show its targeted imaging capable. Adapted with permission from Refs. [20,25].

Among the above metal nanoparticles, gold nanoparticles (AuNPs) are noted for their unique optical and photothermal response properties, excellent electrical conductivity, and good biocompatibility. Their nanocomposites with polymer have been already used for diverse applications, including drug delivery, bioimaging, and tumor treatment [30]. In a recent example, Aili et al. [31] demonstrated the tunable functionalization of bacterial nanocellulose (BC) membranes with AuNPs through a self-assembly strategy. Large amounts of AuNPs were adsorbed and diffused into the interior of the BC membranes via electrostatic interactions to form red hybrid membranes as illustrated in Figure 3a. Interestingly, the resulting nanocomposites exhibited unique mechanoplasmonic properties. The pressure applied on the BC-AuNPs membranes results in tunable spectral variations and enhanced broadband absorption, which is attributed to the increase in the near-field coupling between the immobilized AuNPs. Not restricted to spherical AuNPs, this assembly strategy can be further extended to the loading of AgNPs, and anisotropic gold nanorods and nanoprisms. The resulting BC-metal NP nanocomposites are tailored for diverse properties such as antimicrobial properties, excellent senor performance, and tunable optical properties.

As a typical example of metal oxide nanoparticles, $\mathrm{Fe}_{3} \mathrm{O}_{4}$ nanoparticles have been extensively studied as a promising candidate for diverse applications, including magnetic resonance imaging (MRI), magnetic drug delivery, and catalysts [32]. Yen et al. [33] fabricated a self-assembly hybrid nanoparticle for dual-modal imaging by combining magnetic $\mathrm{Fe}_{3} \mathrm{O}_{4}$ nanoparticles and a NIR fluorescent dye (Figure $3 \mathrm{~b}$ ). It was demonstrated that $\mathrm{Fe}_{3} \mathrm{O}_{4} @$ Dye-Pol displayed lower cytotoxicity than $\mathrm{Fe}_{3} \mathrm{O}_{4}$ nanoparticles, and could be used to label cancer cells for NIR fluorescence microscopy and enhance negative contrast for T2-weighted MR imaging. In addition, $\mathrm{Fe}_{3} \mathrm{O}_{4}$ nanoparticles can also be used to design shape memory materials to achieve a fast shape recovery under a magnetic field [34]. 
(a)
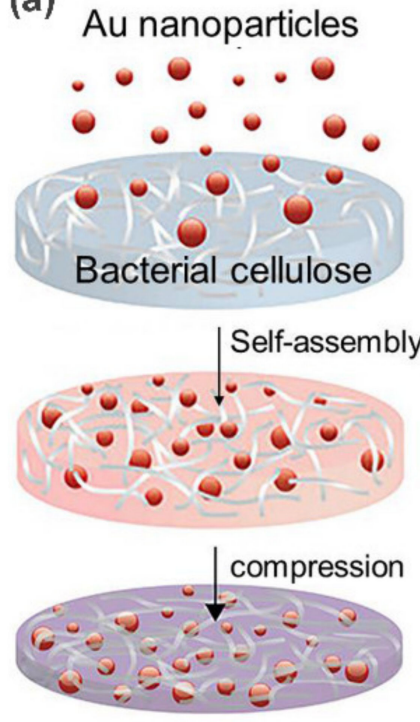
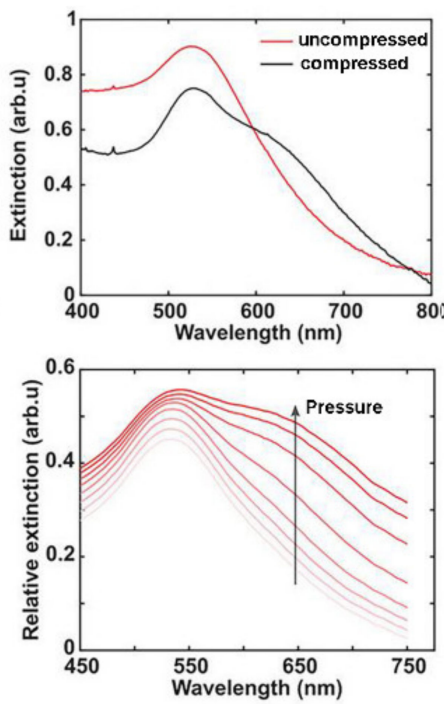

(b)
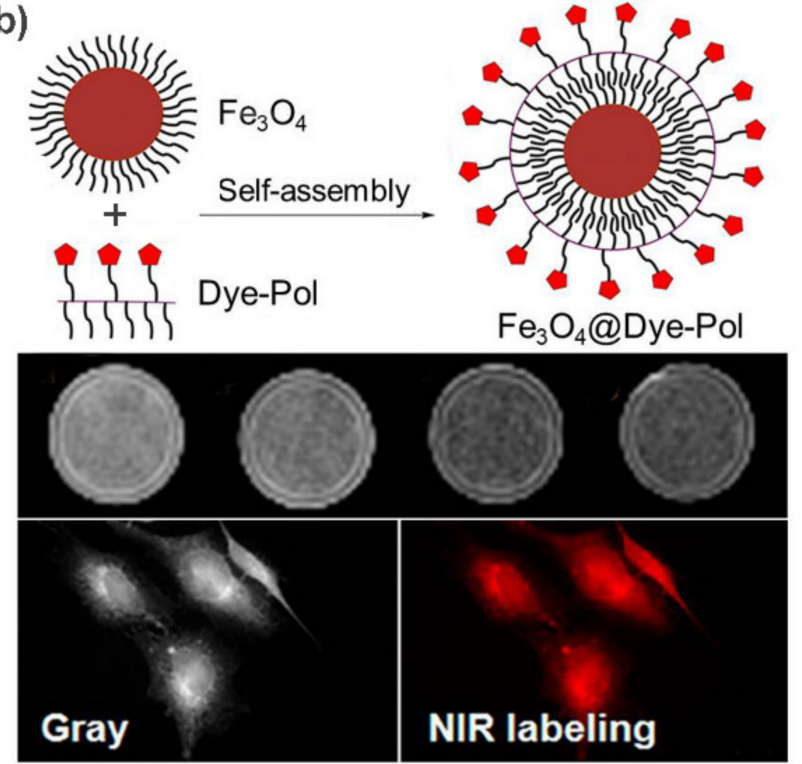

Figure 3. (a) Fabrication of mechanoplasmonic-responsive BC-AuNPs nanocomposite membranes. UV-vis spectra show the pressure-induced redshift in peak position. (b) Schematic illustration of the hybrid nanoparticle formation directed by hydrophobic interactions. MR imaging and NIR imaging results with $\mathrm{Fe}_{3} \mathrm{O}_{4} @$ Dye-Pol. Adapted with permission from Refs. [31,33].

\subsection{Other Nanoparticle/Nanostructure-Based Supramolecular Polymer Nanocomposites}

Some other nanoparticles or nanostructures have also greatly enriched the types and functions of supramolecular polymer nanocomposites. For example, rare earth-doped upconversion nanoparticles (UCNPs) are another alternative fluorescent additive [35,36]. Their anti-Stokes shifts by near-infrared excitation are expected to make up for the deficiency of QDs, making their nanocomposites ideal candidates for in vivo fluorescence imaging probes. Metal-organic frameworks (MOFs) are known for their ultra-high porosity, as well as their tunable structure and functionality. Therefore, coating MOF nanoparticles with polymer network may generate reinforced drug delivery systems with specific performance [37]. Additionally, magnetic properties can be obtained when using GdMOF nanoparticles as an additive. The resulting nanocomposites have great potential as contrast agents of MRI [38]. In comparison to the above rigid nanomaterials, polymeric nano-assembly structures such as micelles, liposomes, and nanogels exhibit many desirable properties including good biocompatibility, physicochemical stability, biodegradability, and excellent flexibility. Because of their unique structures, they are also able to encapsulate hydrophilic or hydrophobic drugs, and thus are appropriate for developing drug delivery systems $[39,40]$. Some examples will be presented later in the therapeutic delivery section.

In general, supramolecular polymer nanocomposites exhibit many improved properties as compared to their components. As discussed above, these improvements are mainly reflected in three aspects: (1) the integration of the properties of each component; (2) the increased strength mainly attributed to the interfacial interactions between the polymer chains and the hybrid nanofillers; and (3) the dynamic and tunable structures mainly endowed by supramolecular interactions. In addition, multifunctional integration can be achieved easily through the rational integration of multiple reinforcing materials. Actually, the materials obtained in this way are currently more popular. They can better meet the requirements of complex production practices and have been widely used in various fields.

\section{Biomedical Applications}

A desirable biomedical material must have prominent biocompatibility, and highly tailored properties and functionalities to meet a wide variety of targeted biomedical needs. 
In this regard, supramolecular polymer nanocomposites have great potential as candidates for such applications. Polymers, especially those from natural origins, are known to have excellent biodegradability and biocompatibility, which are of great importance for in vivo applications. Furthermore, the stimuli-responsive capability, adequate mechanical strength as well as many special properties desired by biomedicine (e.g., optical, electrical, thermal, magnetic, catalytic, and antibacterial characteristics) can also be obtained when combining polymers with dynamic supramolecular interactions and diverse functional nanomaterials. In this section, we highlight the recent examples of these reinforced supramolecular polymer nanocomposites for biomedical applications, including therapeutic delivery, bioimaging, and tissue engineering.

\subsection{Therapeutic Delivery}

Supramolecular polymer nanocomposites have been widely used for therapeutic purposes in recent years. There are many advantages to using supramolecular polymer nanocomposites in cancer-related therapy and drug delivery. As drug carriers, they exhibit typical stimuli-responsive behavior and can serve as smart carriers to control the targeted and on-demand release of drugs by various internal and external stimuli (e.g., $\mathrm{pH}$, light, redox agents, hot, electric field, enzyme, etc.) [41]. Besides the drug encapsulation and release, supramolecular polymer nanocomposites can also achieve multifunctional integration by combining multiple nanofillers. In this way, a variety of traditional and new emerging therapy strategies, such as chemotherapy, radiotherapy, photothermal therapy and photodynamic therapy can be integrated for combinational therapies.

For example, Zhao et al. [42] developed a $\mathrm{pH}$-triggered drug release system by incorporating $\mathrm{pH}$-responsive diblock copolymer (PEG- $b$-poly(2-( $N, N$-diisopropylamino)ethyl methacrylate) micelles into agarose hydrogels (Figure 4a). The core of the micelle serves as a hydrophobic microenvironment for specific incorporation of hydrophobic drugs, and the subsequent protonation of tertiary ammonia at low $\mathrm{pH}$ cause $\mathrm{pH}$-induced dissociation of micelles to achieve ultimately controlled release. Taking Nile Red as a model drug, the fluorescence emission intensity decreased gradually with time when the hybrid gel was treated with a buffer at $\mathrm{pH} 3.3$ until the Nile Red was completely released after $41 \mathrm{~h}$. Another example was reported by Che et al. based on coordination polymer coated MSNs (Figure $4 \mathrm{~b}$ ) [43]. The crucial difference in this work, however, is the $\mathrm{pH}$-responsive characteristic derived from the coordination between polymer layers and MSNs rather than the intrinsic $\mathrm{pH}$ sensitivity of the polymer. Similarly, many other types of stimulus-responsive drug delivery systems have been built. In the case of carbon nanotube-based delivery systems, Mandal and coworkers embedded SWCNTs within a crosslinker-free silk hydrogel. Based on the electrical and thermal properties of carbon nanotubes, as well as the hydrogen bonds and electrostatic interactions between SWCNT and DOX, they successively realized the controlled release of DOX in response to $\mathrm{pH}$, heat, NIR light and electric field [44,45].

Targeted drug delivery is an important technique for efficient cancer therapy. Polymer nanocomposites with superparamagnetic characteristics are particularly attractive as they can be directed and localized under the control of an external magnetic field to achieve magnetically targeted drug delivery [32]. For example, an interesting magnetic delivery system was developed by the co-assembly of $\beta$-cyclodextrin ( $\beta-C D)$ decorated superparamagnetic iron oxide nanoparticles ( $\beta$-CD-SPION) and polymerized paclitaxel (pPTX) [46]. As shown in Figure 4c, the obtained nanocomposites (pPTX/CD-SPION) can act as an efficient magnetic nanovector to enrich PTX in tumor regions and significantly inhibit the tumor growth. Clearly, traditional targeting strategies that rely on biologically targeted small molecules (e.g., RGD and folate) are also applicable to the supramolecular polymer nanocomposite systems $[44,45,47]$. This is even easier to achieve due to the convenience of polymer functionalization. 

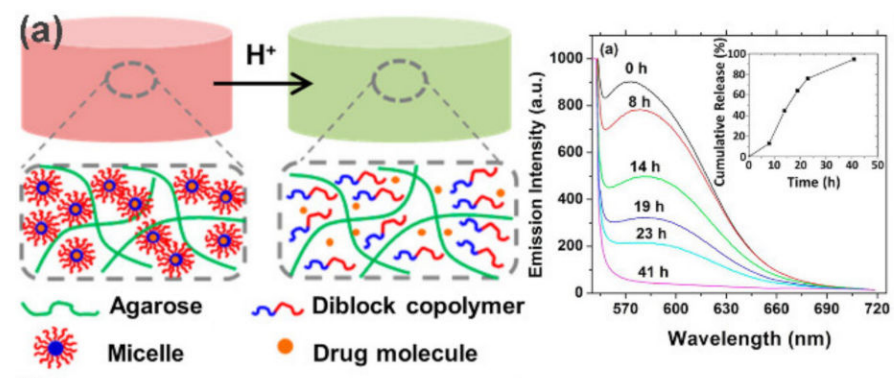

(b)
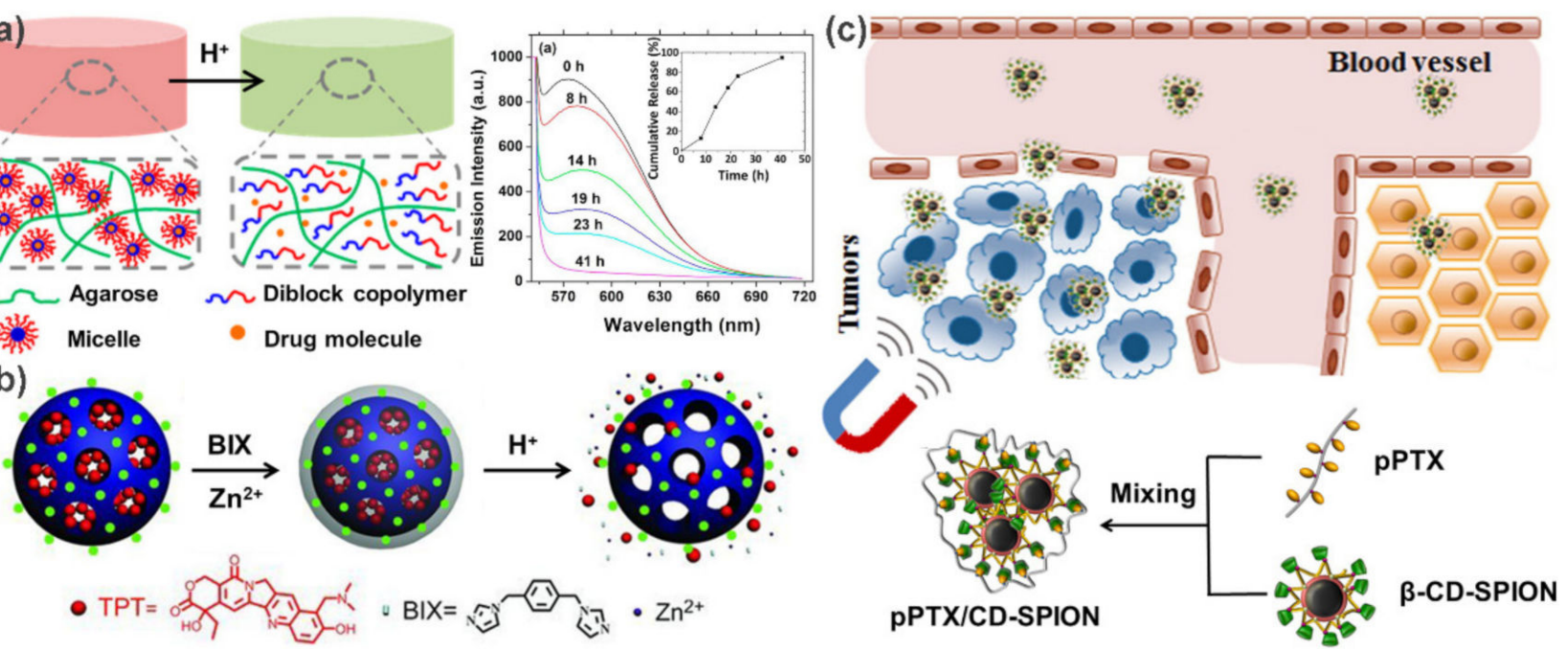

Figure 4. Controlled drug delivery systems for cancer theranostics. (a) Agarose hydrogels embedded with pH-responsive micelles for $\mathrm{pH}$-triggered drug release. (b) Schematic illustration of the preparation and $\mathrm{pH}$-responsive release of coordination polymer coated MSNs. (c) Schematic illustration of the fabrication of pPTX/CD-SPION nano-assemblies and their application in magnetically guided drug delivery. Adapted with permission from Refs. [42,43,46].

With the deepening of research, multimodal synergistic therapy has attracted more and more attention. Compared to the corresponding monotherapy, a better therapeutic effect can be obtained when more therapies are combined in a specific pattern and sequence to yield the synergistic effects. Supramolecular polymer nanocomposites show distinct advantages in this respect. Yan and coworkers realized the purpose of "one injection, multiple treatments" based on a self-assembling collagen-gold hybrid hydrogel [48]. The collagen hybrid hydrogel was formed by gold-biomineralization-triggered self-assembly (Figure 5). Benefitting from the non-covalent driving forces and the photothermal effect of AuNPs, the formed hydrogel is able to serve as a low-toxic injectable material for both drug delivery and photothermal therapy. Subsequently, the strategy of photodynamic therapy (PDT) was proposed when photosensitive drug such as Meso-Tetra ( $N$-methyl4-pyridyl) porphine tetrachloride (TMPyP) was employed as a model drug. An obvious synergistic therapy efficacy against MCF-7 tumors in mice was observed, as the tumor growth was significantly inhibited and some tumors were even completely eradicated after $23 \mathrm{~d}$ of treatment.

\subsection{Bioimaging}

Bioimaging is a powerful technology for visualizing life activities in situ at a cellular or even subcellular level, and plays a vital role in drug tracking and tumor monitoring in the biomedical field. Compared to small molecular probes and conventional polymer probes, the bioimaging probes based on supramolecular polymer nanocomposites often simultaneously possess many important features, such as biocompatibility, target specificity, stimulus responsiveness, and diversity. Specific contrast agents or functional components can be incorporated as desired to prepare diverse bioimaging probes, such as fluorescent components for fluorescence imaging [49,50], paramagnetic components for MRI [51,52], infrared absorbing agents for photoacoustic (PA) imaging [53], and X-ray absorbing agents for computed tomography (CT) imaging [54].

Currently, QD-reinforced supramolecular polymer nanocomposites are being actively explored for fluorescence imaging. For example, Wang and coworkers [49] prepared a matrix metalloproteinase (MMP) responsive cancer cell fluorescence imaging probe by embedding QDs into supramolecular gelatin nanoparticles (SGNs) (Figure 6a). In this work, a microfluidic platform was employed for the preparation process. By altering the flow rates and physiochemical parameters of components, size-controllable QDs@SGNs were generated. These QDs@SGNs nanocomposites were pre-crosslinked with glutaralde- 
hyde, and thus exhibited sufficient stability. Owing to the sensitivity of SGNs to MMP, this probe exhibits high specificity for tumor cells. In the absence of MMP inhibitors, the fluorescence intensity of cells treated with QDs@SGNs is 1.5 times higher than that in the presence of MMP inhibitors. Additionally, QDs can be released and further internalized to illuminate cells when the gelatin matrix was degraded by MMPs. This work presents a typical proteinase-responsive fluorescence imaging example, in which the QDs@SGNs probes are specifically accumulated at target sites and then self-activate their optical signals. Additionally, UCNPs are widely exploited for fluorescence imaging, in view of their unique upconversion luminescent property. For instance, Lin et al. [50] fabricated a hybrid luminescent probe by coating UCNPs with the self-assembled poly(acrylic acid) (PAA) shells (Figure 6b). A highly efficient upconversion luminescence imaging capacity was observed in the following vitro/in vivo experiments.
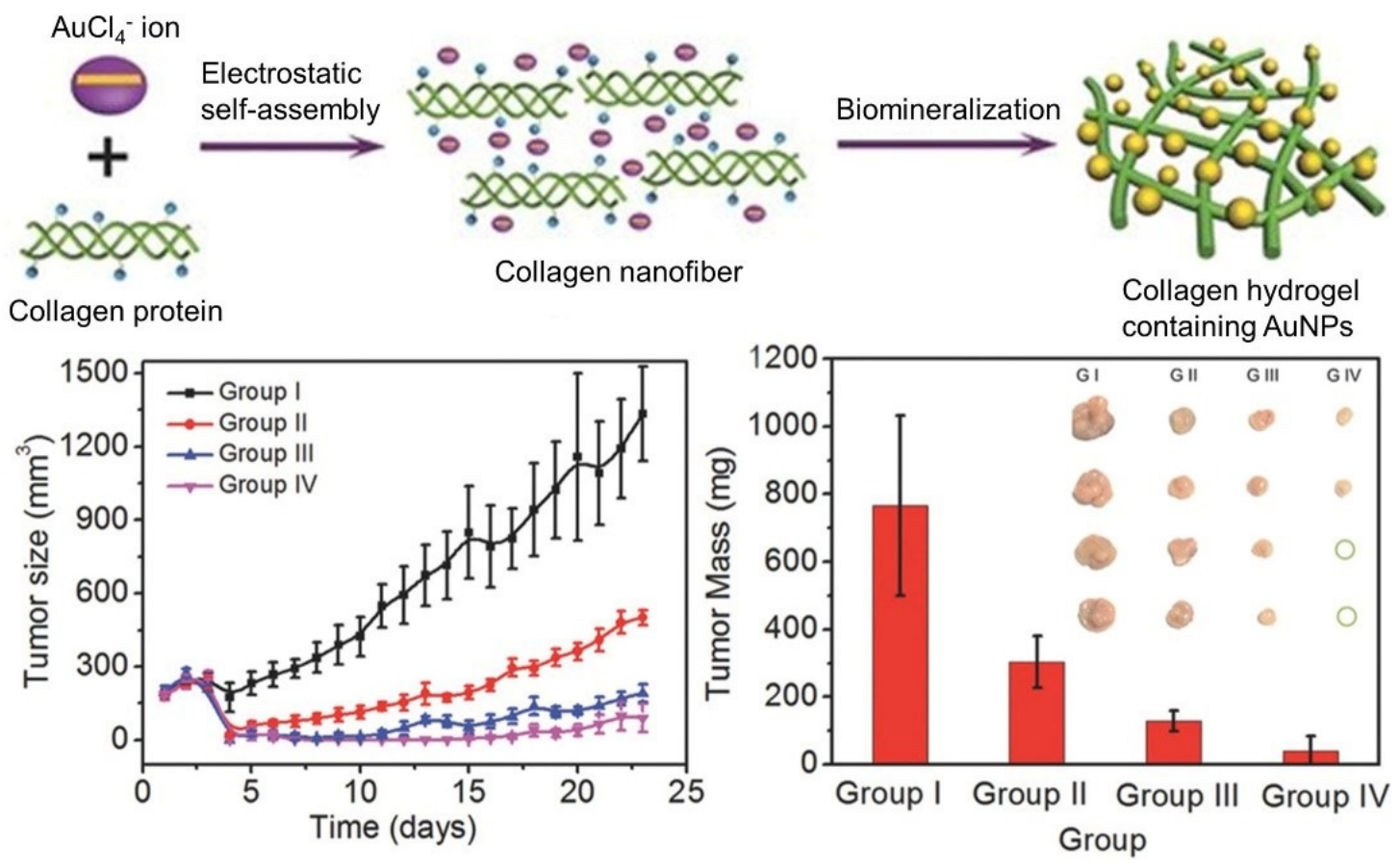

Figure 5. Schematic representation of the formation process of injectable AuNPs-collagen nanocomposite hydrogel via electrostatic self-assembly and biomineralization. Tumor volumes and weights after different treatments demonstrated the synergistic therapy efficacy of PTT/PDT against MCF-7 tumors. Adapted with permission from Ref. [48].

Magnetic supramolecular polymer nanocomposites can be used as contrast agents for enhancing MRI. Using Mn-doped superparamagnetic iron oxide (Mn-SPIO) nanoparticles as filler, Ai et al. [51] fabricated an ultrasensitive MRI contrast agent for liver imaging (Figure 6c). In this work, hydrophobic Mn-SPIO nanocrystals were self-assembled into small clusters with the help of amphiphilic methoxy poly(ethylene glycol)- $b$-poly(3caprolactone) (mPEG- $b-\mathrm{PCL}$ ) and finally formed micellar clustering nanocomposites. In vivo MRI study indicated that T2-weighted signal intensity in liver decreased about $80 \%$ at $5 \mathrm{~min}$ and the time window for enhanced-MRI lasted up to $36 \mathrm{~h}$ after intravenous administration of Mn-SPIO micelles in mice. These advantages make it possible for these nanocomposites to be used for the identification of small liver lesions.

Recently, simultaneous drug delivery and bioimaging function for both therapeutic and diagnostic purposes has received much attention because it may achieve better anticancer efficacy. A typical example of such systems was described by Li et al. [55], who constructed a novel multifunctional supramolecular hybrid nanocarrier with synergetic gene and drug co-delivery, and simultaneous cellular imaging function (Figure 7). In this design, a coreshell fluorescent probe ( $\beta$-CD-OEI@QD) can be prepared by electrostatically coating a red QD with a star-shaped cationic $\beta$-CD polymer ( $\beta$-CD-OEI). Taking advantage of the robust 
guest binding capacity of $\beta-C D$ cavity and their positive surfaces, the resultant $\beta-C D$ OEI@QD complex is able to function as a carrier for co-delivery of paclitaxel (PTX) and gene. In addition, the fluorescence imaging function allows the localization and tracking of the delivery systems in living cells. Because PTX and the gene behave in a co-operative way, a great enhancement in the gene expression is achieved for efficient cancer therapy. Similarly, Chu et al. [56] reported multifunctional theranostic microcapsules prepared by layer-by-layer self-assembly of magnetite $\left(\mathrm{Fe}_{3} \mathrm{O}_{4}\right)$ and supramolecular polymers, which display the double functions of $\mathrm{pH}$-responsive MRI, and UV light-responsive drug delivery.

(a)

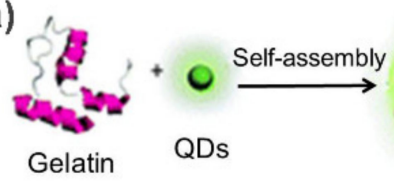

(b)
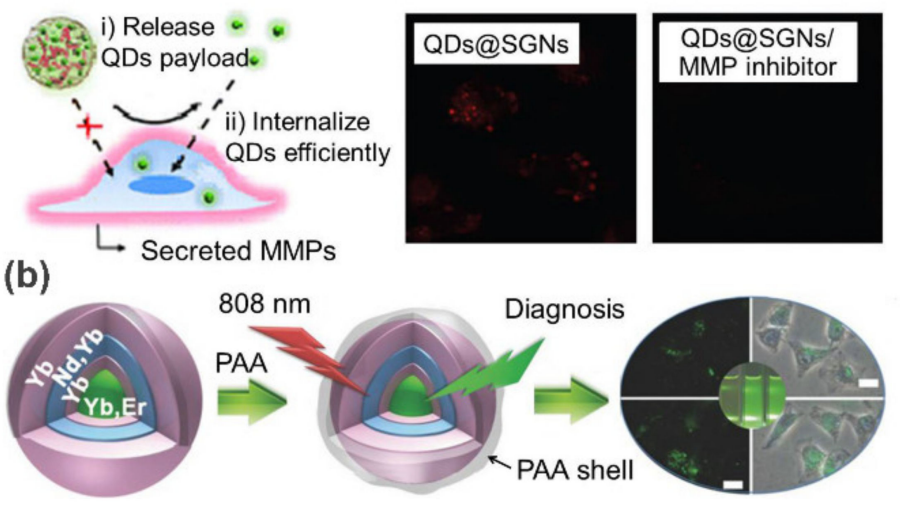

(c)

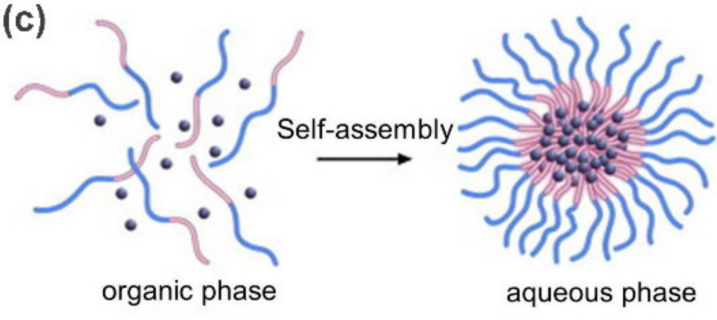

hydrophobic hydrophilic mPEG-b-PCL

- Mn-SPIO nanoparticle

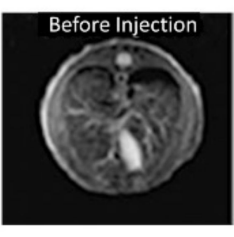

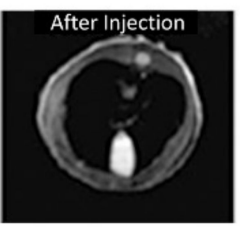

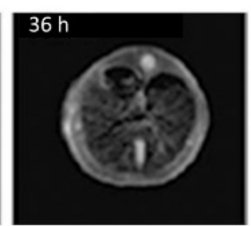

Figure 6. (a) Schematic illustration of the preparation of CdSe quantum dots encapsulated supramolecular gelatin nanoparticles. Fluorescent confocal microscopic images demonstrated that QDs were released and further internalized by cancer cells. (b) Schematic illustration of the preparation of core-shell UCNP@PAA nanoparticles and their application in fluorescence imaging. (c) The formation of hybrid micelles via self-assembly of Mn-doped superparamagnetic iron oxide (Mn-SPIO) nanoparticles and amphiphilic polymer (mPEG- $b-\mathrm{PCL}$ ). MRI imaging results with the Mn-SPIO micelles. Adapted with permission from Refs. [49-51].

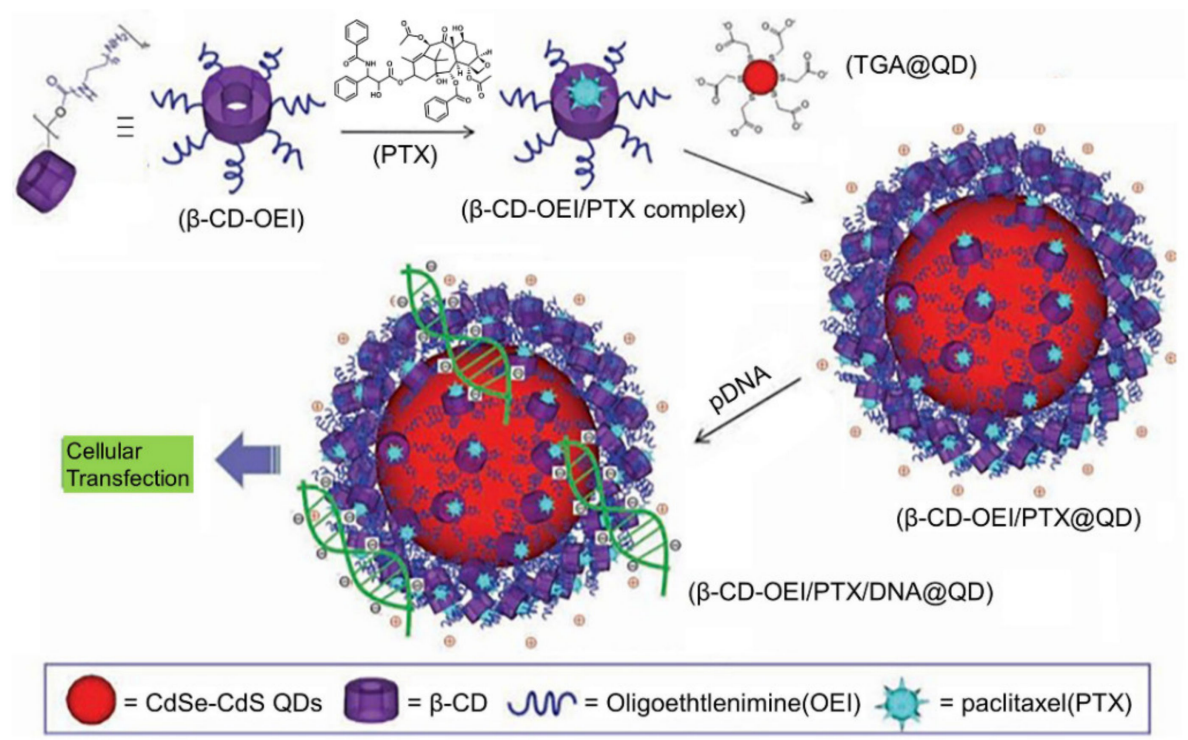

Figure 7. Schematic representation of the fabrication of multifunctional hybrid nanocarrier with simultaneous paclitaxel/gene co-delivery and cellular imaging functions. Adapted with permission from Ref. [55]. 


\subsection{Tissue Engineering}

Tissue engineering has emerged as a new field in medical science that aims at creating artificial tissues and organs for graft replacement. This process requires suitable scaffolds to provide 3D support for cell seeding, proliferation, and differentiation. To satisfy the needs of tissue engineering, the designed scaffolds should have the following key characteristics: excellent biocompatibility and biodegradability for in vivo applications; highly porous structures for cellular migration and proliferation; well-matched mechanical strength and elasticity with surrounding tissues; cell-biomaterial interactions; and in the ideal case, the controlled stimulation of the anticipated biological response. Supramolecular polymer nanocomposites are a promising candidate for tissue engineering application in this regard, especially because of their special capability to combine biodegradable polymers (synthetic and natural) with diverse nanofillers. In the past few decades, several bioactive nanomaterials including calcium phosphate, bioactive glasses, silica NPs, nanoclays, and carbon-based nanomaterials were chosen and involved in the construction of composite scaffolds [57-59]. Accordingly, numerous bioactive scaffolds based on supramolecular polymer nanocomposites with tailored functionality were generated and have been widely used in both hard (e.g., bone and tooth) [60-62] and soft (e.g., cartilage, nerves, muscular, cardiac, skin, and blood vessels) [63-66] tissues engineering. Meanwhile, a class of fascinating injectable materials emerged [67-69]. They are certainly a wise choice for tissue engineering, because they are capable of filling irregular tissue defects in a minimally invasive fashion.

Bone tissue engineering is an important branch of tissue engineering. Inspired by natural bone, the combination of biodegradable polymers with bioactive ceramic nanoparticles is a typical approach to construct artificial bone engineering scaffolds. As an example, Leeuwenburgh et al. [60] examined the effect of bisphosphonate (BP) and bioactive glass on the regeneration of osteoporotic bone defects. In this work, injectable composite gels were fabricated through the self-assembly of BP-functionalized gelatin and bioactive glass particles (Figure 8a). In vitro experiments showed that the composite gels could induce apatite formation, and facilitate proliferation and differentiation of osteoblastic cells in the absence of exogenous osteogenic supplement. Furthermore, the regenerative capacity was confirmed when more apparent formation of vascularized bone was observed inside femoral condyle defects, suggesting their ability for the treatment of osteoporotic bone defects. Similarly, the self-assembled composite nanoparticle hydrogel that contains chitosan and calcium phosphate was also used for mesenchymal stem cell-based bone tissue engineering [61]. This scaffold can effectively support MSC proliferation in vitro and markedly promoted BMP9-induced bone formation in vivo.

Benefitting from the anisotropic structures and large interacting surfaces, nanoclays are widely used in bone tissue engineering in order to obtain hybrid scaffolds with excellent biocompatibility, enhanced strength, and hierarchical structures. For instance, Liu et al. [62] used 3D printing technology to construct high strength polymer/nanoclay bioscaffolds for bone regeneration (Figure $8 \mathrm{~b}$ ). A hybrid ink with both $N$-acryloyl glycinamide (NAGA) and nanoclay (Laponite XLG) was developed to print PNAGA-nanoclay 3D scaffolds. Remarkably, the final composite scaffolds exhibit superior mechanical performances, in which the tensile strength and Young's modulus reach 1.17 and 0.18 MPa when the NAGA content is $30 \%$. This can be attributed to the dual interaction networks of $\mathrm{H}$-bonding and nanoclay-polymer chain linkage. In vitro experiments showed that $\mathrm{Mg}^{2+}$ and $\mathrm{Si}^{4+}$ were continuously released from the PNAGA-Clay scaffold, thus facilitating the osteogenic differentiation of osteoblast cells. Histological observations of implanting PNAGA-Clay scaffold in a rat tibia model showed the formation of abundant new bone around the defect area, which demonstrating their ability for bone regeneration.

In light of their excellent electrical conductivity, carbon-based nanomaterials such as graphene and CNTs can be exploited in the design of electroactive bioscaffolds for neural, muscular, and cardiac tissue engineering [70,71]. Jin et al. [63] reported 3D electrically conductive nanofibers that were fabricated by electrostatically wrapping electrospun polymer nanofibers with GO sheets and followed by a chemical reduction (Figure 9a). 
As expected, the resulting composite nanofibers (G-NFs) show excellent electrical and mechanical properties. The maximum electrical conductivity reaches $12.5 \pm 1.2 \mathrm{~S} \cdot \mathrm{cm}^{-1}$ and the Young's modulus $(5.3 \pm 1.2 \mathrm{GPa})$ is similar to that of natural collagen fibers. Subsequently, G-NFs were evaluated as a soft cell modulation scaffold for neural tissue engineering, where the growth and development of motor neurons have been significantly accelerated when electrical stimulation $(100 \mathrm{mV})$ was applied. In another example, the rGO was incorporated into gelatin methacrylyol (GelMA) matrix through hydrophobic interactions (Figure 9b) [64]. The resulting composite rGO-GelMA scaffolds not only possess enhanced electrical conductivity and mechanical properties, but also exhibit excellent cell adhesion, proliferation, and maturation. Therefore, rGO-GelMA can be used as conductive hydrogels for cardiac tissue engineering.

(a)
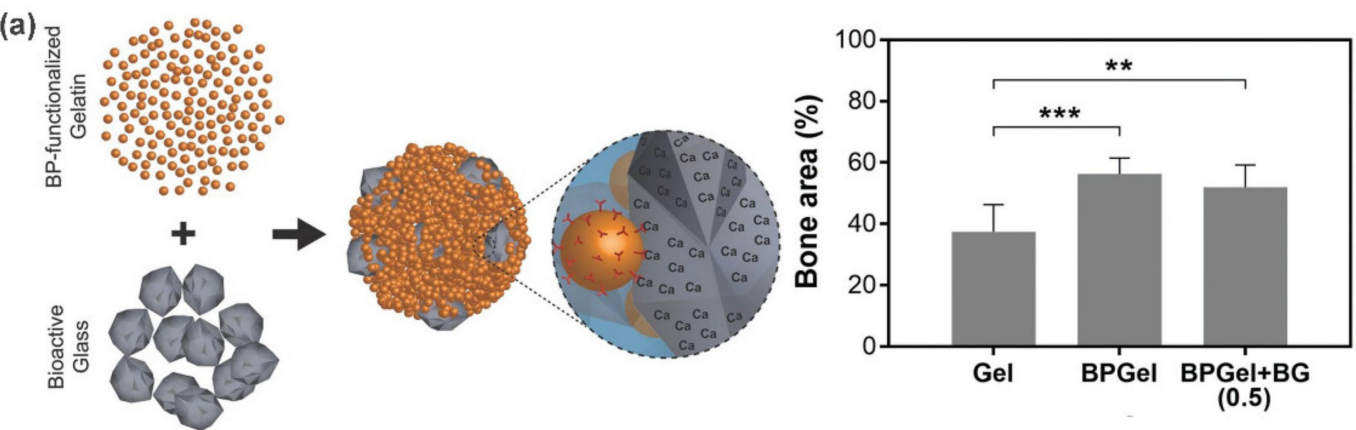

(b)
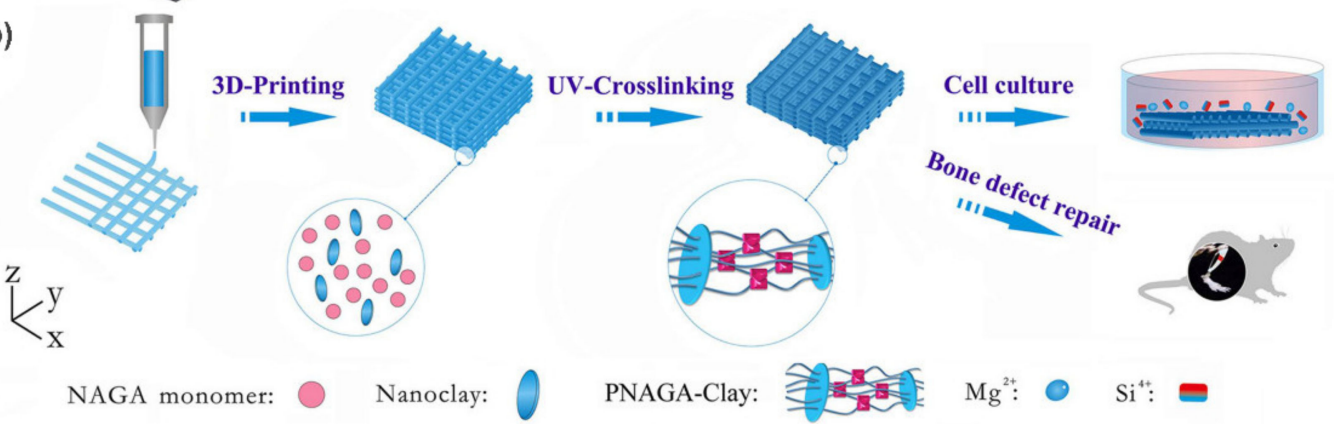

Figure 8. Preparation of bioscaffolds for bone tissue engineering applications. (a) Schematic illustration of the formation of injectable composite gels composed of BP-functionalized gelatin and bioactive glass. The increase in bone area confirmed their capacity to support the regeneration of osteoporotic bone defects. (b) Schematic illustration of the fabrication process of 3D-printing PNAGA-Clay scaffolds and their application in bone tissue engineering. Adapted with permission from Refs. [60,62].

Tissue engineering scaffolds with therapeutic functions are more attractive due to their ability to replace the lesion tissue and to inhibit the recurrence of tumor. As a typical example, Liu et al. [67] reported an injectable supramolecular polymer nanocomposite hydrogel with NIR light-stimulated drug delivery and photothermal therapy for breast reconstruction and breast tumor recurrence inhibition. As shown in Figure 10, This hydrogel was fabricated by entrapping polydopamine coated-gold nanoparticles (PDA-AuNPs) into poly(N-acryloyl glycinamide-co-acrylamide) (PNAGA-PAAm) hydrogel. Consequently, the hybrid hydrogels not only achieve enhanced mechanical properties due to the covalent and non-covalent interactions between PDA and polymer network, but also exhibit CT self-imaging capacity and superior photothermal effect derived from PDA-AuNPs. The photothermal effect can cause locoregional heating to break the physical crosslinking and further result in a quick gel-sol transition. Therefore, efficient drug delivery can be triggered by the illumination of NIR light. The cumulative DOX release in tumor-like microenvironment was identified to be $82.7 \%$, more than twice the amount of the control groups. Moreover, the compressive moduli of the PNAm-PDAAu hydrogel reaches the same order of magnitude as human breast tissue, showing a great potential for serving as a mammoplastic filler. 
(a)

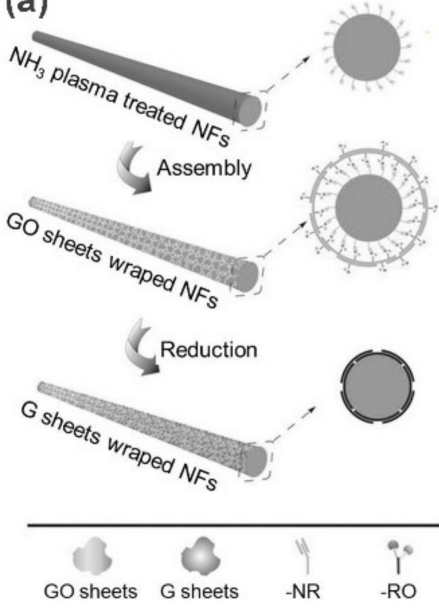

(b)
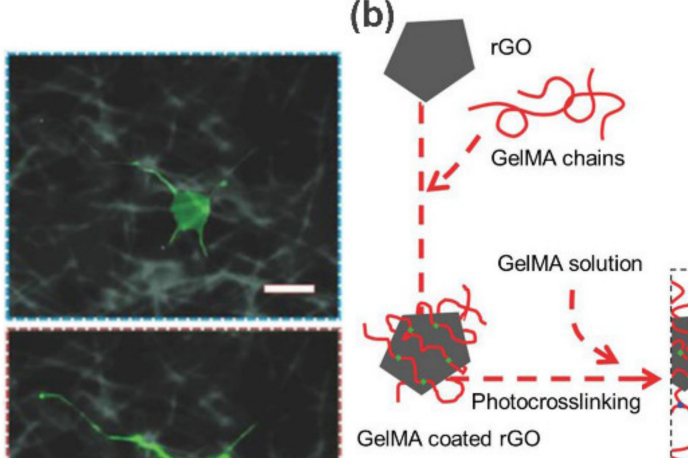

- Covalent crosslink Hydrophobic interaction

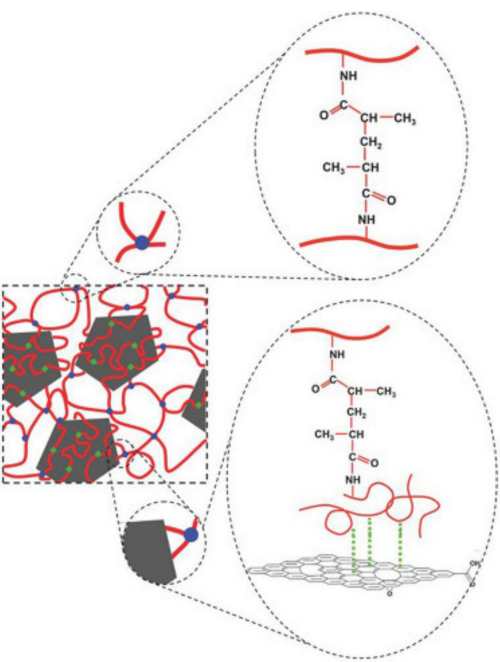

Figure 9. Preparation of electroactive bioscaffolds for soft tissue engineering applications. (a) Schematic illustration of the fabrication process of GO reinforced composite nanofibers G-NFs. Fluorescence images of the cells on G-NFs before and after pulse. (b) Preparation procedure of rGO-GelMA hybrid hydrogels. Adapted with permission from Refs. [63,64].

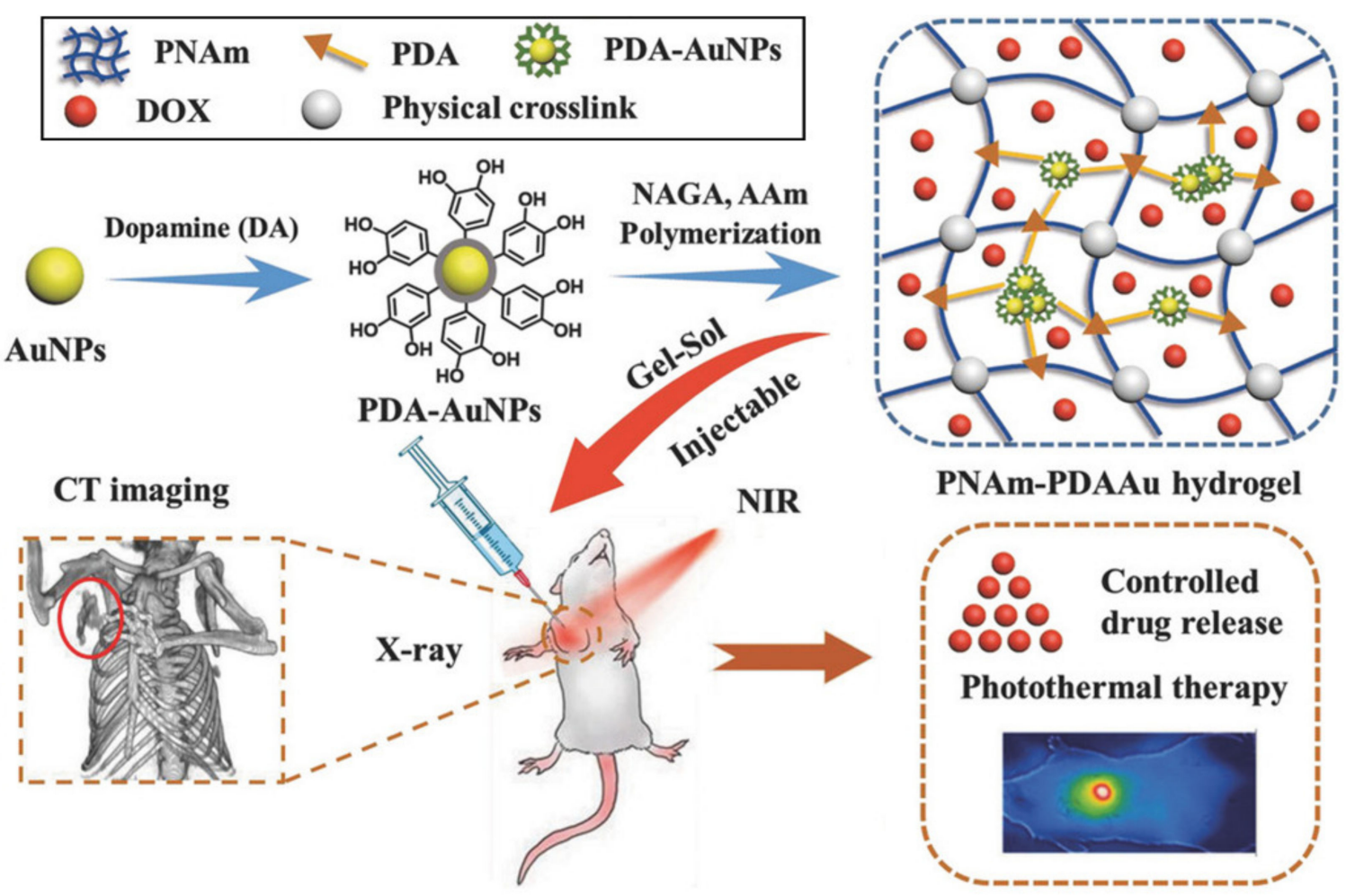

Figure 10. Schematic illustration of the fabrication of PNAm-PDAAu nanocomposite hydrogel and its application as a cancerous breast filler with simultaneous self-imaging and therapeutic functions. Adapted with permission from Ref. [67].

\section{Conclusion and Outlook}

This review focuses on the current progress of supramolecular polymer nanocomposites. Based on the huge diversity and versatility of polymers and nanofillers, the combination of the two has greatly enriched the types and functions of nanocomposite materials. Additionally, the introduction of supramolecular chemistry further endows polymer nanocomposites with dynamics and adjustability for various applications, especially biomedicine, as shown in the previous discussion. First of all, the encapsulation of polymer 
can effectively reduce the possible biotoxicity of nanomaterials to satisfy the basic biocompatibility for biological applications. Secondly, supramolecular polymer nanocomposites are not only versatile carriers for targeted delivery and controlled release of the therapeutic agents, but also perfect candidates for multimode diagnosis and treatment platforms, with the capability of simultaneous multimode synergistic therapy and in vivo imaging. Finally, versatile bioscaffolds for tissue engineering can be rationally constructed by supramolecular polymer nanocomposites with tailored mechanical properties, degradation profiles, and some special bioactives, depicting a bright application prospect for hard and soft tissue repair and regeneration.

Despite significant progress, many challenges still exist. Throughout the developing trend and orientation of supramolecular polymer nanocomposites, in our opinion, there are two key issues that should be addressed in the future. (i) Precise control over structures and properties. Biomedical applications impose strict criteria for such nanocomposite materials, including accuracy in the distribution of nanofillers, as well as the predictability in the acquisition of functions and properties. This will absolutely depend on a deeper understanding of structure-function relationships, as well as the hierarchical assembly strategy similar to nature or more advanced preparation technologies in the future. (ii) Clinical practice. The ultimate goal is to apply them to clinical practice. However, current studies on supramolecular polymer nanocomposites are still preliminary. Moving forward, many crucial problems such as toxicity, biodistribution, biodegradation, and clearance need to be fully evaluated via a large number of in vivo studies before they are applied in clinical diagnosis and treatment. Even so, we are certain that these hurdles will eventually be overcome with the intimate collaboration between scientists in various disciplines.

Author Contributions: Conceptualization, Quan Luo and Xiumei Li; writing—original draft preparation, Xiumei Li and Wanjia Xu; writing-review and editing, Yue Xin, Jiawei Yuan, Yuancheng Ji and Shengnan Chu; supervision, Quan Luo and Junqiu Liu; funding acquisition, Quan Luo. All authors have read and agreed to the published version of the manuscript.

Funding: This work was funded by National Key R\&D Program of China (Grant No. 2020YFA0907003, 2018YFA0901600, and YS2020YFA090023), Natural Science Foundation of China (No. 21871109), the Science Development Program of Jilin Province (No. 20180201062SF and 20200403063SF), and Key Laboratory of Emergency and Trauma (Hainan Medical University), Ministry of Education (Grant. KLET-202012).

Institutional Review Board Statement: Not applicable.

Informed Consent Statement: Not applicable.

Data Availability Statement: The data presented in this study are available on request from the corresponding author.

Conflicts of Interest: The authors declare no conflict of interest.

\section{References}

1. Paul, D.R.; Robeson, L.M. Polymer nanotechnology: Nanocomposites. Polymer 2008, 49, 3187-3204. [CrossRef]

2. Kumar, S.; Sarita Nehra, M.; Dilbaghi, N.; Tankeshwar, K.; Kim, K.-H. Recent advances and remaining challenges for polymeric nanocomposites in healthcare applications. Prog. Polym. Sci. 2018, 80, 1-38. [CrossRef]

3. Mittal, G.; Dhand, V.; Rhee, K.Y.; Park, S.-J.; Lee, W.R. A review on carbon nanotubes and graphene as fillers in reinforced polymer nanocomposites. J. Ind. Eng. Chem. 2015, 21, 11-25. [CrossRef]

4. Li, S.; Meng Lin, M.; Toprak, M.S.; Kim, D.K.; Muhammed, M. Nanocomposites of polymer and inorganic nanoparticles for optical and magnetic applications. Nano Rev. 2010, 1, 5214. [CrossRef]

5. Dziadek, M.; Stodolak-Zych, E.; Cholewa-Kowalska, K. Biodegradable ceramic-polymer composites for biomedical applications: A review. Mater. Sci. Eng. C 2017, 71, 1175-1191. [CrossRef]

6. Qi, W.; Zhang, X.; Wang, H. Self-assembled polymer nanocomposites for biomedical application. Curr. Opin. Colloid Interface Sci. 2018, 35, 36-41. [CrossRef]

7. Wang, D.; Tong, G.; Dong, R.; Zhou, Y.; Shen, J.; Zhu, X. Self-assembly of supramolecularly engineered polymers and their biomedical applications. Chem. Commun. 2014, 50, 11994-12017. [CrossRef] 
8. Li, M.; Luo, Z.; Zhao, Y. Self-assembled hybrid nanostructures: Versatile multifunctional nanoplatforms for cancer diagnosis and therapy. Chem. Mater. 2018, 30, 25-53. [CrossRef]

9. Molina, M.; Asadian-Birjand, M.; Balach, J.; Bergueiro, J.; Miceli, E.; Calderon, M. Stimuli-responsive nanogel composites and their application in nanomedicine. Chem. Soc. Rev. 2015, 44, 6161-6186. [CrossRef]

10. Strong, L.E.; West, J.L. Thermally responsive polymer-nanoparticle composites for biomedical applications. Wiley Interdiscip. Rev. Nanomed. Nanobiotechnol. 2011, 3, 307-317. [CrossRef]

11. Papageorgiou, D.G.; Li, Z.; Liu, M.; Kinloch, I.A.; Young, R.J. Mechanisms of mechanical reinforcement by graphene and carbon nanotubes in polymer nanocomposites. Nanoscale 2020, 12, 2228-2267. [CrossRef]

12. Sahoo, N.G.; Rana, S.; Cho, J.W.; Li, L.; Chan, S.H. Polymer nanocomposites based on functionalized carbon nanotubes. Prog. Polym. Sci. 2010, 35, 837-867. [CrossRef]

13. Kim, H.; Abdala, A.A.; Macosko, C.W. Graphene/polymer nanocomposites. Macromolecules 2010, 43, 6515-6530. [CrossRef]

14. Zhang, Y.-F.; Du, F.-P.; Chen, L.; Yeung, K.-W.; Dong, Y.; Law, W.-C.; Tsui, G.C.-P.; Tang, C.-Y. Supramolecular ionic polymer/carbon nanotube composite hydrogels with enhanced electromechanical performance. Nanotechnol. Rev. 2020, 9, 478-488. [CrossRef]

15. Yang, C.; Liu, Z.; Chen, C.; Shi, K.; Zhang, L.; Ju, X.-J.; Wang, W.; Xie, R.; Chu, L.-Y. Reduced graphene oxide-containing smart hydrogels with excellent electro-response and mechanical properties for soft actuators. ACS Appl. Mater. Interfaces 2017, 9, 15758-15767. [CrossRef]

16. Du, R.; Wu, J.; Chen, L.; Huang, H.; Zhang, X.; Zhang, J. Hierarchical hydrogen bonds directed multi-functional carbon nanotube-based supramolecular hydrogels. Small 2014, 10, 1387-1393. [CrossRef] [PubMed]

17. Han, D.; Yan, L. Supramolecular hydrogel of chitosan in the presence of graphene oxide nanosheets as $2 \mathrm{D}$ cross-linkers. ACS Sustain. Chem. Eng. 2014, 2, 296-300. [CrossRef]

18. Sarno, M.; Baldino, L.; Scudieri, C.; Cardea, S.; Ciambelli, P.; Reverchon, E. Supercritical $\mathrm{CO}_{2}$ processing to improve the electrochemical properties of graphene oxide. J. Supercrit. Fluids 2016, 118, 119-127. [CrossRef]

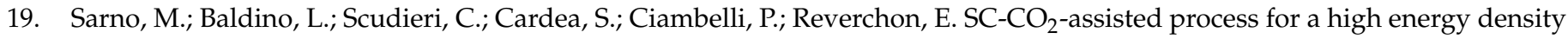
aerogel supercapacitor: The effect of GO loading. Nanotechnology 2017, 28, 204001-204013. [CrossRef] [PubMed]

20. Wu, Y.; Shah, D.U.; Liu, C.; Yu, Z.; Liu, J.; Ren, X.; Rowland, M.J.; Abell, C.; Ramage, M.H.; Scherman, O.A. Bioinspired supramolecular fibers drawn from a multiphase self-assembled hydrogel. Proc. Natl. Acad. Sci. USA. 2017, 114, 8163-8168. [CrossRef]

21. Wang, Q.; Mynar, J.L.; Yoshida, M.; Lee, E.; Lee, M.; Okuro, K.; Kinbara, K.; Aida, T. High-water-content mouldable hydrogels by mixing clay and a dendritic molecular binder. Nature 2010, 463, 339-343. [CrossRef] [PubMed]

22. Yuan, W.; Li, Z.; Xie, X.; Zhang, Z.-Y.; Bian, L. Bisphosphonate-based nanocomposite hydrogels for biomedical applications. Bioact. Mater. 2020, 5, 819-831. [CrossRef]

23. Rahaman, M.N.; Day, D.E.; Bal, B.S.; Fu, Q.; Jung, S.B.; Bonewald, L.F.; Tomsia, A.P. Bioactive glass in tissue engineering. Acta Biomater. 2011, 7, 2355-2373. [CrossRef]

24. Kairdolf, B.A.; Smith, A.M.; Stokes, T.H.; Wang, M.D.; Young, A.N.; Nie, S. Semiconductor quantum dots for bioimaging and biodiagnostic applications. Annu. Rev. Anal. Chem. 2013, 6, 143-162. [CrossRef] [PubMed]

25. Yang, J.; Yao, M.-H.; Wen, L.; Song, J.-T.; Zhang, M.-Z.; Zhao, Y.-D.; Liu, B. Multifunctional quantum dot-polypeptide hybrid nanogel for targeted imaging and drug delivery. Nanoscale 2014, 6, 11282-11292. [CrossRef] [PubMed]

26. Faupel, F.; Zaporojtchenko, V.; Strunskus, T.; Elbahri, M. Metal-polymer nanocomposites for functional applications. Adv. Eng. Mater. 2010, 12, 1177-1190. [CrossRef]

27. Arvizo, R.R.; Bhattacharyya, S.; Kudgus, R.A.; Giri, K.; Bhattacharya, R.; Mukherjee, P. Intrinsic therapeutic applications of noble metal nanoparticles: Past, present and future. Chem. Soc. Rev. 2012, 41, 2943-2970. [CrossRef] [PubMed]

28. Nenadovic, M.; Potocnik, J.; Mitric, M.; Strbac, S.; Rakocevic, Z. Modification of high density polyethylene by gold implantation using different ion energies. Mater. Chem. Phys. 2013, 142, 633-639. [CrossRef]

29. Hanemann, T.; Szabo, D.V. Polymer-nanoparticle composites: From synthesis to modern applications. Materials 2010, 3, 3468-3517. [CrossRef]

30. Guerrero, A.R.; Hassan, N.; Escobar, C.A.; Albericio, F.; Kogan, M.J.; Araya, E. Gold nanoparticles for photothermally controlled drug release. Nanomedicine 2014, 9, 2023-2039. [CrossRef]

31. Eskilson, O.; Lindström, S.B.; Sepulveda, B.; Shahjamali, M.M.; Güell-Grau, P.; Sivlér, P.; Skog, M.; Aronsson, C.; Björk, E.M.; Nyberg, N. Self-assembly of mechanoplasmonic bacterial cellulose-metal nanoparticle composites. Adv. Funct. Mater. 2020, 30, 2004766. [CrossRef]

32. Kalia, S.; Kango, S.; Kumar, A.; Haldorai, Y.; Kumari, B.; Kumar, R. Magnetic polymer nanocomposites for environmental and biomedical applications. Coll. Polym. Sci. 2014, 292, 2025-2052. [CrossRef]

33. Yen, S.K.; Janczewski, D.; Lakshmi, J.L.; Dolmanan, S.B.; Tripathy, S.; Ho, V.H.; Vijayaragavan, V.; Hariharan, A.; Padmanabhan, P.; Bhakoo, K.K. Design and synthesis of polymer-functionalized NIR fluorescent dyes-magnetic nanoparticles for bioimaging. ACS Nano 2013, 7, 6796-6805. [CrossRef] [PubMed]

34. Wang, Y.; Ye, J.; Tian, W. Shape memory polymer composites of poly (styrene-b-butadiene-b-styrene) copolymer/liner low density polyethylene $/ \mathrm{Fe}_{3} \mathrm{O}_{4}$ nanoparticles for remote activation. Appl. Sci. 2016, 6, 333. [CrossRef] 
35. Cheng, Z.; Lin, J. Synthesis and application of nanohybrids based on upconverting nanoparticles and polymers. Macromol. Rapid Commun. 2015, 36, 790-827. [CrossRef]

36. Ma, P.a.; Xiao, H.; Li, X.; Li, C.; Dai, Y.; Cheng, Z.; Jing, X.; Lin, J. Rational design of multifunctional upconversion nanocrystals/polymer nanocomposites for cisplatin (IV) delivery and biomedical imaging. Adv. Mater. 2013, 25, 4898-4905. [CrossRef] [PubMed]

37. Beg, S.; Rahman, M.; Jain, A.; Saini, S.; Midoux, P.; Pichon, C.; Ahmad, F.J.; Akhter, S. Nanoporous metal organic frameworks as hybrid polymer-metal composites for drug delivery and biomedical applications. Drug Discov. Today 2017, 22, 625-637. [CrossRef]

38. Giliopoulos, D.; Zamboulis, A.; Giannakoudakis, D.; Bikiaris, D.; Triantafyllidis, K. Polymer/metal organic framework (MOF) nanocomposites for biomedical applications. Molecules 2020, 25, 185. [CrossRef]

39. Zhao, F.; Yao, D.; Guo, R.; Deng, L.; Dong, A.; Zhang, J. Composites of polymer hydrogels and nanoparticulate systems for biomedical and pharmaceutical applications. Nanomaterials 2015, 5, 2054-2130. [CrossRef] [PubMed]

40. Gaharwar, A.K.; Peppas, N.A.; Khademhosseini, A. Nanocomposite hydrogels for biomedical applications. Biotechnol. Bioeng. 2014, 111, 441-453. [CrossRef]

41. Merino, S.; Martin, C.; Kostarelos, K.; Prato, M.; Vazquez, E. Nanocomposite hydrogels: 3D polymer-nanoparticle synergies for on-demand drug delivery. ACS Nano 2015, 9, 4686-4697. [CrossRef]

42. Jin, N.; Morin, E.A.; Henn, D.M.; Cao, Y.; Woodcock, J.W.; Tang, S.; He, W.; Zhao, B. Agarose hydrogels embedded with $\mathrm{pH}$-responsive diblock copolymer micelles for triggered release of substances. Biomacromolecules 2013, 14, 2713-2723. [CrossRef]

43. Xing, L.; Zheng, H.; Cao, Y.; Che, S. Coordination polymer coated mesoporous silica nanoparticles for pH-responsive drug release. Adv. Mater. 2012, 24, 6433-6437. [CrossRef]

44. Gangrade, A.; Gawali, B.; Jadi, P.K.; Naidu, V.G.; Mandal, B.B. Photo-electro active nanocomposite silk hydrogel for spatiotemporal controlled release of chemotherapeutics: An in vivo approach towards suppressing solid tumor growth. ACS Appl. Mater. Interfaces 2020, 12, 27905-27916. [CrossRef] [PubMed]

45. Gangrade, A.; Mandal, B.B. Injectable carbon nanotube impregnated silk based multifunctional hydrogel for localized targeted and on-demand anticancer drug delivery. ACS Biomater. Sci. Eng. 2019, 5, 2365-2381. [CrossRef]

46. Jeon, H.; Kim, J.; Lee, Y.M.; Kim, J.; Choi, H.W.; Lee, J.; Park, H.; Kang, Y.; Kim, I.-S.; Lee, B.-H. Poly-paclitaxel/cyclodextrin-SPION nano-assembly for magnetically guided drug delivery system. J. Control Release 2016, 231, 68-76. [CrossRef]

47. Wang, X.-G.; Dong, Z.-Y.; Cheng, H.; Wan, S.-S.; Chen, W.-H.; Zou, M.-Z.; Huo, J.-W.; Deng, H.-X.; Zhang, X.-Z. A multifunctional metal-organic framework based tumor targeting drug delivery system for cancer therapy. Nanoscale 2015, 7, 16061-16070. [CrossRef]

48. Xing, R.; Liu, K.; Jiao, T.; Zhang, N.; Ma, K.; Zhang, R.; Zou, Q.; Ma, G.; Yan, X. An injectable self-assembling collagen-gold hybrid hydrogel for combinatorial antitumor photothermal/photodynamic therapy. Adv. Mater. 2016, 28, 3669-3676. [CrossRef] [PubMed]

49. Xu, J.-H.; Gao, F.-P.; Liu, X.-F.; Zeng, Q.; Guo, S.-S.; Tang, Z.-Y.; Zhao, X.-Z.; Wang, H. Supramolecular gelatin nanoparticles as matrix metalloproteinase responsive cancer cell imaging probes. Chem. Commun. 2013, 49, 4462-4464. [CrossRef]

50. Liu, B.; Chen, Y.; Li, C.; He, F.; Hou, Z.; Huang, S.; Zhu, H.; Chen, X.; Lin, J. Poly (acrylic acid) modification of Nd ${ }^{3+}$-sensitized upconversion nanophosphors for highly efficient UCL imaging and pH-responsive drug delivery. Adv. Funct. Mater. 2015, 25, 4717-4729. [CrossRef]

51. Lu, J.; Ma, S.; Sun, J.; Xia, C.; Liu, C.; Wang, Z.; Zhao, X.; Gao, F.; Gong, Q.; Song, B. Manganese ferrite nanoparticle micellar nanocomposites as MRI contrast agent for liver imaging. Biomaterials 2009, 30, 2919-2928. [CrossRef]

52. Chen, J.; Shi, M.; Liu, P.; Ko, A.; Zhong, W.; Liao, W.; Xing, M.M. Reducible polyamidoamine-magnetic iron oxide self-assembled nanoparticles for doxorubicin delivery. Biomaterials 2014, 35, 1240-1248. [CrossRef]

53. Qin, H.; Zhang, W.; Luo, Y.; Wei, Y.; Sun, S.; Chen, J. The performance of composite nanoparticles based on $\mathrm{Fe}_{3} \mathrm{O}_{4} @ \mathrm{SiO}_{2} / \mathrm{PLGA} / \mathrm{PFOB}$ in magnetic resonance imaging and photoacoustic imaging. Sci. Adv. Mater. 2019, 11, 1816-1824. [CrossRef]

54. An, J.; Yang, X.-Q.; Cheng, K.; Song, X.-L.; Zhang, L.; Li, C.; Zhang, X.-S.; Xuan, Y.; Song, Y.-Y.; Fang, B.-Y.; et al. In Vivo computed tomography/photoacoustic imaging and NIR-triggered chemo-photothermal combined therapy based on a gold nanostar-, mesoporous silica-, and thermosensitive liposome-composited nanoprobe. ACS Appl. Mater. Interfaces 2017, 9, 41748-41759. [CrossRef] [PubMed]

55. Wu, Y.L.; Yin, H.; Zhao, F.; Li, J. Multifunctional hybrid nanocarriers consisting of supramolecular polymers and quantum dots for simultaneous dual therapeutics delivery and cellular imaging. Adv. Healthcare Mater. 2013, 2, 297-301. [CrossRef] [PubMed]

56. Zheng, D.-W.; Lei, Q.; Chen, S.; Qiu, W.-X.; Liu, M.-Y.; Chen, X.; Ding, Y.-X.; Li, P.-H.; Zhang, Q.-Y.; Xu, Z.-S. Supermolecular theranostic capsules for $\mathrm{pH}$-sensitive magnetic resonance imaging and multi-responsive drug delivery. J. Mater. Chem. B 2015, 3 , 8499-8507. [CrossRef]

57. Erol-Taygun, M.; Unalan, I.; Idris, M.I.B.; Mano, J.F.; Boccaccini, A.R. Bioactıve glass-polymer nanocomposites for bone tıssue regeneration applications: A Review. Adv. Eng. Mater. 2019, 21, 1900287. [CrossRef]

58. Wu, C.-J.; Gaharwar, A.K.; Schexnailder, P.J.; Schmidt, G. Development of biomedical polymer-silicate nanocomposites: A materials science perspective. Materials 2010, 3, 2986-3005. [CrossRef]

59. Hopley, E.L.; Salmasi, S.; Kalaskar, D.M.; Seifalian, A.M. Carbon nanotubes leading the way forward in new generation 3D tissue engineering. Biotechnol. Adv. 2014, 32, 1000-1014. [CrossRef] [PubMed] 
60. Diba, M.; Camargo, W.A.; Brindisi, M.; Farbod, K.; Klymov, A.; Schmidt, S.; Harrington, M.J.; Draghi, L.; Boccaccini, A.R.; Jansen, J.A. Composite colloidal gels made of bisphosphonate-functionalized gelatin and bioactive glass particles for regeneration of osteoporotic bone defects. Adv. Funct. Mater. 2017, 27, 1703438. [CrossRef]

61. Zhao, C.; Qazvini, N.T.; Sadati, M.; Zeng, Z.; Huang, S.; De La Lastra, A.L.; Zhang, L.; Feng, Y.; Liu, W.; Huang, B. A pH-triggered, self-assembled, and bioprintable hybrid hydrogel scaffold for mesenchymal stem cell based bone tissue engineering. ACS Appl. Mater. Interfaces 2019, 11, 8749-8762. [CrossRef]

62. Zhai, X.; Ma, Y.; Hou, C.; Gao, F.; Zhang, Y.; Ruan, C.; Pan, H.; Lu, W.W.; Liu, W. 3D-printed high strength bioactive supramolecular polymer/clay nanocomposite hydrogel scaffold for bone regeneration. ACS Biomater. Sci. Eng. 2017, 3, 1109-1118. [CrossRef]

63. Feng, Z.Q.; Wang, T.; Zhao, B.; Li, J.; Jin, L. Soft graphene nanofibers designed for the acceleration of nerve growth and development. Adv. Mater. 2015, 27, 6462-6468. [CrossRef] [PubMed]

64. Shin, S.R.; Zihlmann, C.; Akbari, M.; Assawes, P.; Cheung, L.; Zhang, K.; Manoharan, V.; Zhang, Y.S.; Yuksekkaya, M.; Wan, K.-t.; et al.'Reduced graphene oxide-gelma hybrid hydrogels as scaffolds for cardiac tissue engineering. Small 2016, 12, 3677-3689. [CrossRef]

65. Mehrali, M.; Thakur, A.; Pennisi, C.P.; Talebian, S.; Arpanaei, A.; Nikkhah, M.; Dolatshahi-Pirouz, A. Nanoreinforced hydrogels for tissue engineering: Biomaterials that are compatible with load-bearing and electroactive tissues. Adv. Mater. 2017, $29,1603612$. [CrossRef] [PubMed]

66. Navaei, A.; Saini, H.; Christenson, W.; Sullivan, R.T.; Ros, R.; Nikkhah, M. Gold nanorod-incorporated gelatin-based conductive hydrogels for engineering cardiac tissue constructs. Acta Biomater. 2016, 41, 133-146. [CrossRef] [PubMed]

67. Wu, Y.; Wang, H.; Gao, F.; Xu, Z.; Dai, F.; Liu, W. An injectable supramolecular polymer nanocomposite hydrogel for prevention of breast cancer recurrence with theranostic and mammoplastic functions. Adv. Funct. Mater. 2018, 28, 1801000. [CrossRef]

68. Hu, X.; Li, D.; Tan, H.; Pan, C.; Chen, X. Injectable graphene oxide/graphene composite supramolecular hydrogel for delivery of anti-cancer drugs. J. Macromol. Sci. Part A Pure Appl. Chem. 2014, 51, 378-384. [CrossRef]

69. Sui, K.; Gao, S.; Wu, W.; Xia, Y. Injectable supramolecular hybrid hydrogels formed by MWNT-grafted-poly (ethylene glycol) and alpha-cyclodextrin. J. Polym. Sci. Part A Polym. Chem. 2010, 48, 3145-3151. [CrossRef]

70. Ignat, S.R.; Lazar, A.D.; Selaru, A.; Samoila, I.; Vlasceanu, G.M.; Ionita, M.; Radu, E.; Dinescu, S.; Costache, M. Versatile biomaterial platform enriched with graphene oxide and carbon nanotubes for multiple tissue engineering applications. Int. J. Mol. Sci. 2019, 20, 3868. [CrossRef]

71. Hitscherich, P.; Aphale, A.; Gordan, R.; Whitaker, R.; Singh, P.; Xie, L.-h.; Patra, P.; Lee, E.J. Electroactive graphene composite scaffolds for cardiac tissue engineering. J. Biomed. Mater. Res. Part A 2018, 106, 2923-2933. [CrossRef] [PubMed] 